\title{
Simulation of the Extraction Efficiency of Coalbed Methane under Water Injection: A Gas-Liquid-Solid Coupling Model
}

\author{
Hai Pu, ${ }^{1,2}$ Liqiang Zhang $\mathbb{D}^{1}{ }^{1}$ Xu Dong, ${ }^{3}$ Tao Jing, ${ }^{1}$ and Xu Junce ${ }^{1}$ \\ ${ }^{1}$ State Key Laboratory for Geomechanics and Deep Underground Engineering, China University of Mining and Technology, \\ Xuzhou 221116, China \\ ${ }^{2}$ College of Mining Engineering and Geology, Xinjiang Institute of Engineering, Urumqi, Xinjiang 830091, China \\ ${ }^{3}$ School of Architecture Engineering, Xuzhou Vocational College of Industrial Technology, Xuzhou 221140, China \\ Correspondence should be addressed to Liqiang Zhang; tb15220011b0@cumt.edu.cn
}

Received 23 August 2019; Revised 19 February 2020; Accepted 25 July 2020; Published 27 September 2020

Academic Editor: Shengnan Nancy Chen

Copyright (C) $2020 \mathrm{Hai}$ Pu et al. This is an open access article distributed under the Creative Commons Attribution License, which permits unrestricted use, distribution, and reproduction in any medium, provided the original work is properly cited.

\begin{abstract}
Coalbed methane is always a major hidden danger that affects mining safety in coal mines. In the study of coal seam water injection to control gas disaster, the increase of free water content is helpful to destroy the integrity of coal seam and to promote the flow of gas in fractures. However, when the free water fills the fracture space, it will increase the flow resistance of gas, and then will reduce the gas extraction efficiency. At present, there is currently no mathematical model describing the effects of coal seam water injection that combines these two aspects on gas drainage. In this study, a series of experiments were conducted to study the differences in mechanical property changes under wetting conditions with different coal samples. The experimental results show that the elastic modulus and compressive strength decrease as an exponential function with increasing water pressure. Based on the experimental results, a gas-liquid-solid coupling model including effective stress change and gas desorption is established and used to predict a field gas extraction application. According to the results of the numerical model, In the plastic failure zone of coal seam, the permeability increases, the elastic modulus drops and gas migrates faster. In the water wetting zone, the free water occupies the fracture space, which blocks the gas migration channel. The overall effect of water injection on gas extraction depends on which impact plays a dominant role. The established gas drainage model is validated by field data and can reflect the pattern of borehole damage and gas drainage under water injection.
\end{abstract}

\section{Introduction}

Coalbed methane (gas) is not only a major hidden danger affecting the safety of mining in coal mines but also an excellent clean energy source. As of 2015, gas outburst accidents accounted for $27 \%$ of the total number of coal mine accidents in China, and the number of mines with coal gas outbursts has reached 1,192 [1]. Therefore, the study of coal seam gas drainage technology can not only prevent coal mine gas disasters in a timely manner but also change harm to benefits and increase the utilization rate of coal gas [2].

At present, the mining protective layer in the mine is the main means of regional gas disaster management and has been widely used underground. Limited by the geologic com- plexity of coal seams, gas control in a single coal seam also needs to be combined with local preextraction of gas, loose blasting, and other local antiburst measures [3]. However, in practice, such measures often face problems, such as low gas concentrations, fast flow attenuation, and the problem of small blasting areas, which make it difficult to quickly reduce the gas content [4].

As a kind of local gas control measure, coal seam water injection has an obvious softening effect on coal seams and reduces gas and coal dust release to the surrounding environment, thereby achieving the goal of quickly eliminating dynamic coal seam disasters. However, coal seam water injection is still associated with great differences in the study of coal and gas outbursts. Most 
researchers and engineers believe that the existence of free water changes the mechanical properties of coal and reduces coal seam cohesion and uniaxial compressive strength, thereby changing the stress distribution of coal seams, further causing fractures in coal seams and promoting the release of methane into the surrounding environment. Fredlund et al. [5], Ji et al. [6], and Kishida et al. [7] carried out experiments on the seepage characteristics of rock under loading and unloading and studied the process of primary fracture propagation and penetration under different water injection pressures. It is pointed out that free water not only promotes the development of fractures but also reduces the compressive strength of rock samples. Deng et al. [8] studied the change in permeability of water-bearing sandstone in the context of confining pressure. The change in permeability is closely related to free water erosion and sandstone damage. Bo et al. [9] and Zhang et al. [10] studied the mechanical properties of rocks under different water saturations and pointed out that rocks with different saturations have effects on the rock elastic modulus and acoustic emission parameters. As the water saturation increases, the rock's peak strength and elastic modulus decrease rapidly.

Other researchers believe that coal seam water injection significantly changes the gas desorption characteristics and closes the adsorption gas desorption channel, thereby reducing the gas drainage efficiency. Peng et al. [11] believe that the axial pressure and water content are the key factors determining the permeability of coal samples. On the one hand, the axial pressure narrows the seepage channel of the gas and completely closes some microcracks. On the other hand, the free water in the coal sample blocks the gas migration channel and further leads to a decrease in the permeability of the coal sample. Letham et al. [12] studied the gas seepage law before and after water injection. On the basis of gas-water two-phase flow, a coalbed methane drainage model considering the gas slippage effect was established. The results show that gas saturation is greatly affected by free water. With the increase in coal seam water injection time and water injection pressure, gas production shows a gradual decline. Oostrom and Lenhard [13] analyzed the effects of free water on gas saturation, relative permeability, and rock mass deformation based on the double pore characteristics of the rock mass. The study pointed out that free water obviously hinders gas migration. The above research results show that the presence of free water inhibits the gas desorption and diffusion process in the reservoir.

It can be seen from the current research that the effect of coal seam water injection on gas drainage has two sides: on the one hand, water injection softens the coal seam and reduces the cohesion and uniaxial compressive strength of coal, which promotes fracture generation in the coal seam and accelerates gas flow; on the other hand, water injection changes the desorption characteristics of the gas in the pores of coal and closes the desorption channel of the pore gas, which reduces the rate of gas diffusion from the pore to the fractures. There is currently no mathematical model describing the effects of coal seam water injection on gas drainage combining these two aspects. Therefore, in this study, we started from the two-phase flow seepage theory and established a gas drainage model for the dual-porosity and dual-permeability characteristics of coal seams under water injection conditions. The effects of fracture initiation and expansion on gas drainage in the plastic failure zone of the coal seam before and after water injection were studied, and the effects of free water plugging the gas migration in the hydraulic wetting zone were analyzed. Based on these results, the variations in coal seam permeability, gas pressure, and flow rate under water injection were obtained.

\section{The Mechanical Properties of the Coal Sample under Water Injection}

Coal seam water injection is an important method to control coal and gas outburst [14]. In this section, we conduct experiments to study the differences in mechanical property changes under wetting conditions between soft coal and hard coal. The coal samples were collected from the Pingdingshan No.10 coal mine in Henan Province and the Gushuyuan coal mine in Shanxi Province, China, and the samples represent typical medium-hard coal and hard coal, respectively.

The experiments were conducted by an electrohydraulic servo triaxial testing machine. The coal samples were subjected to full stress-strain testing in conjunction with water injection. First, the coal sample was placed in the pressure chamber. Then, the confining pressure corresponding to a chosen value is applied, and water is injected into the coal sample at a certain pressure. Finally, an axial load is applied until the coal sample breaks. Additionally, the stress and strain of the coal sample are recorded. The water injection pressures were $0,0.5,1.0$, $1.5,2.0,2.5$, and $3.0 \mathrm{MPa}$, and the confining pressures were $2.0,2.5,3.0,3.5,4.0,4.5$, and $5.0 \mathrm{MPa}$, respectively. These values were chosen to ensure that all the tests were under the same effective stress condition. To eliminate random deviation, we tested three samples at each stress stage. The test results are shown in Figures 1 and 2 .

From Figures 1 and 2, it can be seen that the elastic modulus and uniaxial compressive strength of the coal samples decrease with increasing water content. For the coal samples from the Pingdingshan No. 10 coal mine (soft coal), the elastic modulus drops $46 \%$, and the uniaxial compressive strength drops $28 \%$. For the coal samples from the Gushuyuan coal mine (hard coal), the elastic modulus drops $18 \%$, and the uniaxial compressive strength drops $15 \%$. The experimental results prove that the water content can decrease the mechanical properties of coal and that soft coal is more affected by water than hard rock.

Based on the testing results, the relationship between the elastic modulus and water pressure can be expressed as

$$
E=A_{0} e^{\left(-J_{0} P_{\text {fw }}\right)}+E_{0}
$$

where $E_{0}$ is the residual elastic modulus. Similarly, the 


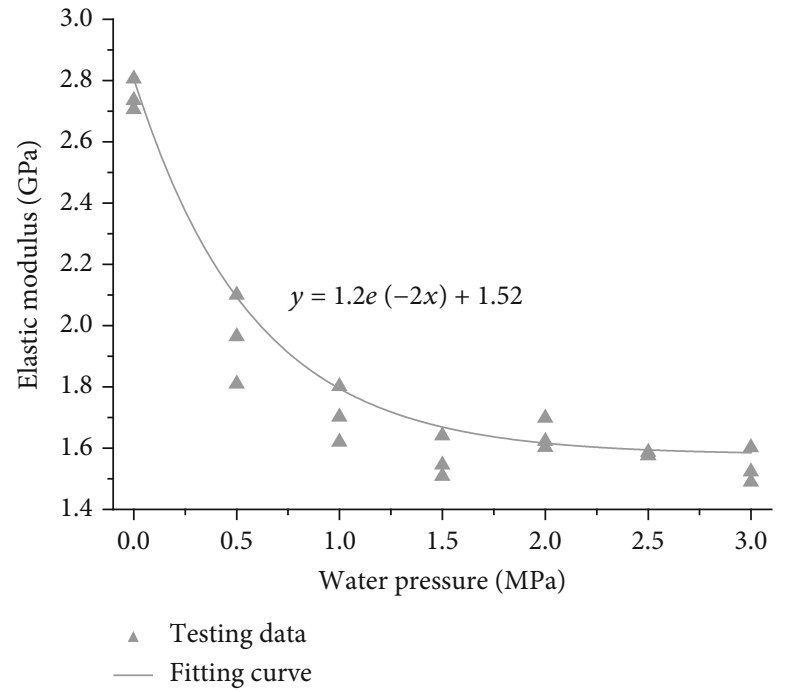

(a)

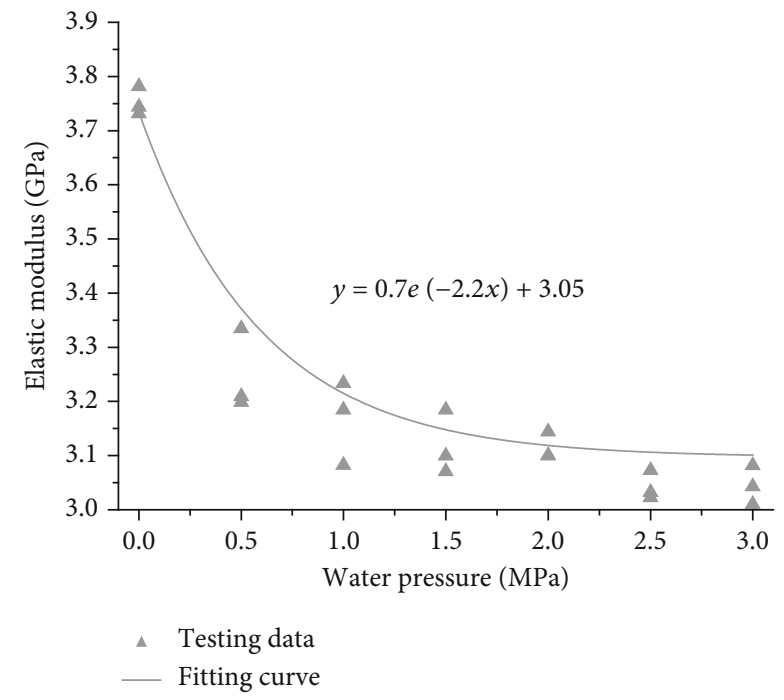

(b)

FIGURE 1: The elastic modulus changes with water injection ((a) coal samples from the Pingdingshan No. 10 coal mine; (b) coal samples from the Gushuyuan coal mine).

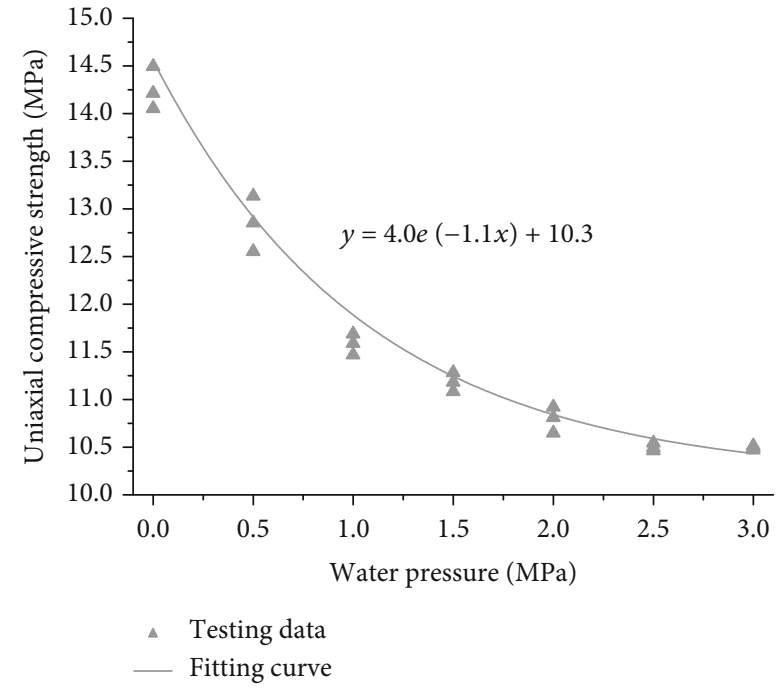

(a)

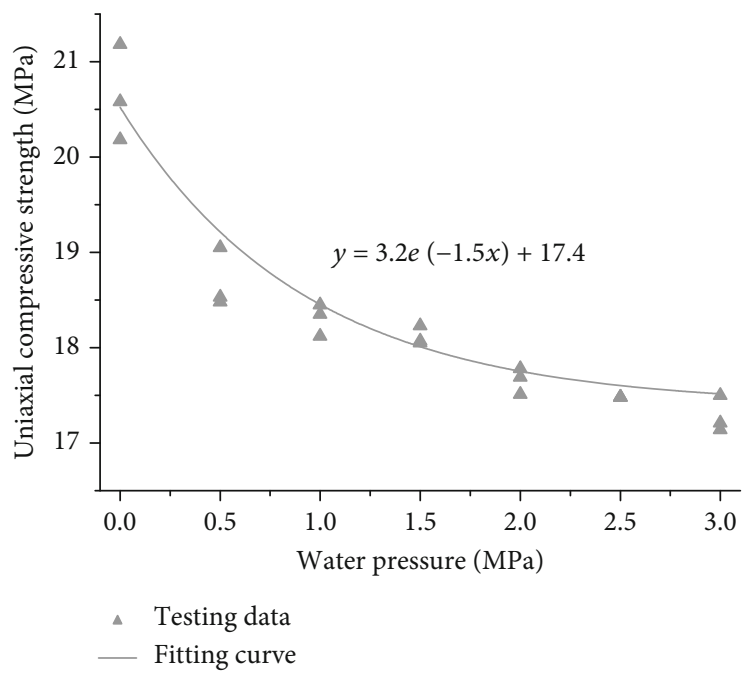

(b)

Figure 2: The uniaxial compressive strength changes with water injection ((a) coal samples from the Pingdingshan No. 10 coal mine; (b) coal samples from the Gushuyuan coal mine).

relationship between uniaxial compressive strength and water pressure can also be expressed as

$$
\sigma_{c}=A_{1} e^{\left(-J_{1} P_{\mathrm{fw}}\right)}+\sigma_{c 0},
$$

where $A_{0}$ and $A_{1}$ are the amplitude of the drop; $J_{0}$ and $J_{1}$ are the attenuation coefficient.

\section{The Gas-Liquid-Solid Coupling Model for Gas Extraction}

As shown in the last section, water injection remarkably changes the mechanical properties of coal. To study the gas extraction of coal seams with water injection, a coupled gas-liquid-solid model considering the two side effects of water injection should be established. The main assumptions are as follows. In the following, a set of field equations for coal deformation, gas flow, and water flow are defined. These field equations are coupled through new porosity and permeability models for the coal matrix and fractures. These derivations are based on the following assumptions [15]:

(1) The coal seam is a homogeneous, isotropic, and dual poroelastic medium

(2) Strains are infinitesimal 


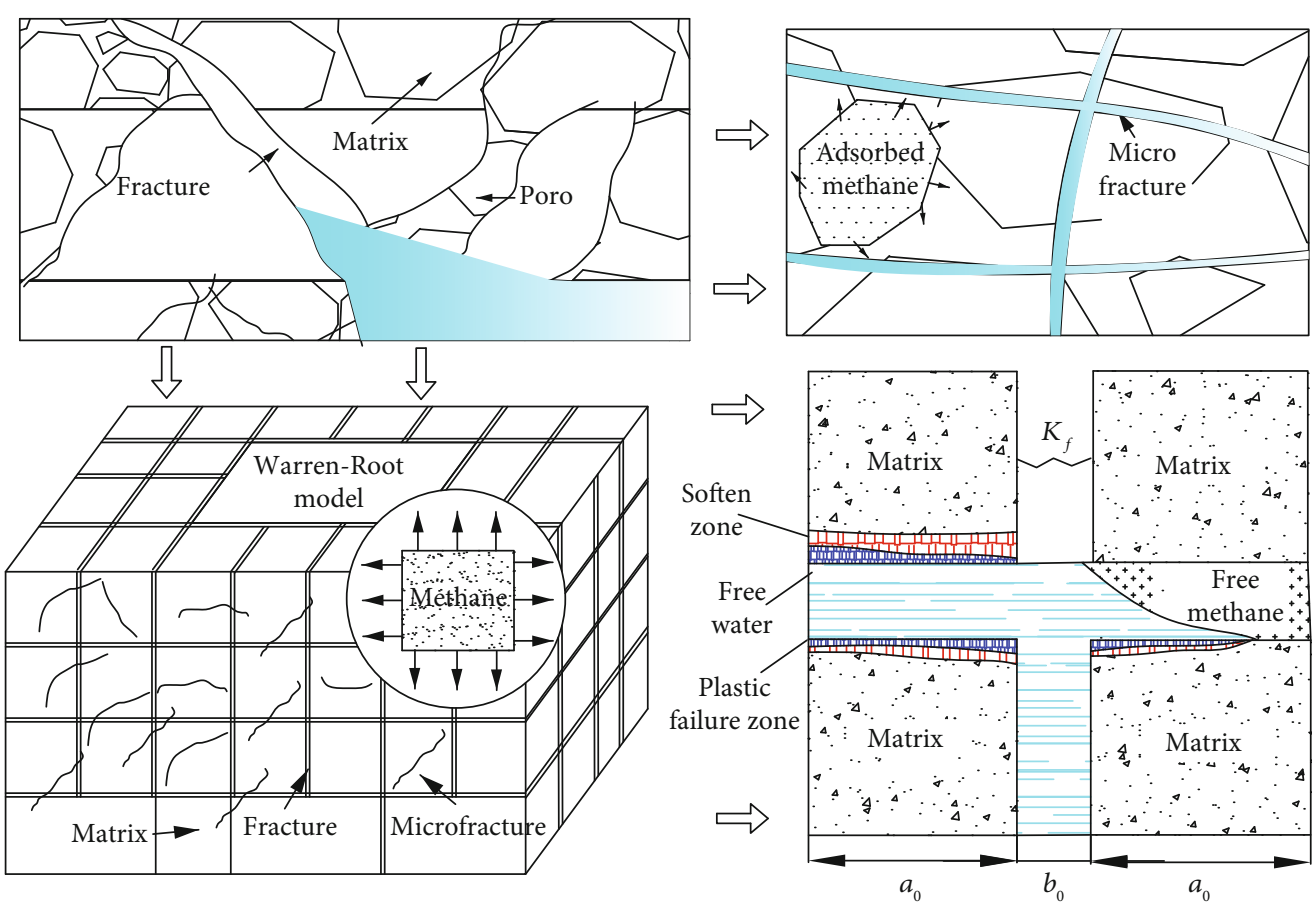

Figure 3: Concept diagram of a coal seam and fluid flow.

(3) Gas contained within the pores is ideal, and its viscosity is constant under isothermal conditions

(4) Gas adsorption only takes place in the matrix

(5) The matrix pores are filled with bound water, which cannot flow. The water flow only occurs in the fracture system. Before water injection, the coal seam has no obvious free water flow

In general, coal seam is a dual-porosity media containing matrix pores and fractures. The natural fractures of coal seam can be divided into horizontal bedding fracture and vertical cleat fracture. Methane is mainly stored in the pores by adsorbing on the micropore surface accounting for $70-95 \%$ of the total reserves. Throughout the water injection process, free water gradually flows along the fractures in the coal seam. Finally, the coal seam fracture contains two kinds of fluids, free water and gas. The flow of the fluid is shown in Figure 3.

3.1. Coal Deformation. During gas drainage in a coal seam, coal deformation can be defined by the equilibrium equation, geometric equation, and constitutive equation. Therefore, by treating coal as an isotropic material, the Navier-type equation for coal deformation can be expressed as follows [16]:

$$
G u_{i, k k}+\frac{G}{1-2 v} u_{k, k i}-\alpha P_{\mathrm{mg}, i}-\beta P_{\mathrm{fg}, i}-\beta P_{\mathrm{fw}, i}-K \varepsilon_{s, i}+f_{, i}=0,
$$

where $G$ is the shear modulus of coal and $v$ is Poisson's ratio. $\alpha$ and $\beta$ are the Biot coefficients [17]. $K$ is the bulk modulus of coal. Subscripts $m$ and $f$ represent the matrix and fracture, respectively. $f_{, i}$ is the component of the body force, and $\varepsilon_{\mathrm{s}}$ is the sorption strain. The parameters can be defined as follows:

$$
\begin{aligned}
& \alpha=1-\frac{K}{K_{s}}, \\
& \beta=1-\frac{K}{a_{0} \cdot K_{f}}, \\
& \varepsilon_{s}=\frac{\varepsilon_{L} P_{\mathrm{mg}}}{P_{\mathrm{mg}}+P_{L}} e^{(-\lambda \theta)},
\end{aligned}
$$

where $K_{s}$ is the bulk modulus of the matrix. $K_{f}$ is the normal stiffness of fracture. The subscript $\mathrm{mg}$, fg, and fw represent gas in the matrix, gas in the fracture, and water in the fracture, respectively. $\lambda$ is the bound water coefficient, and $\theta$ is the water content in porosity.

3.2. Fluid Flow Equations. In a coal seam, gas and water exist in the pores and fractures. The mass of free-phase gas, adsorbed gas, and free water can be written as follows [18]:

$$
\begin{aligned}
M_{\mathrm{mg}} & =\rho_{\mathrm{mg}} \phi_{m}+\rho_{\mathrm{ga}} \rho_{c} \frac{V_{L} P_{\mathrm{mg}}}{P_{\mathrm{mg}}+P_{L}} e^{(-\lambda \theta)}, \\
M_{\mathrm{fg}} & =\rho_{\mathrm{fg}} \phi_{f} S_{\mathrm{fg}}, \\
M_{\mathrm{fw}} & =\rho_{\mathrm{fw}} \phi_{f} S_{\mathrm{fw}},
\end{aligned}
$$

where $\rho_{\mathrm{mg}}$ is the gas density. $\rho_{\mathrm{ga}}$ is the gas density under standard conditions. $\rho_{c}$ is the coal density. $V_{L}$ and $P_{L}$ are Langmuir volume and pressure constants. $P_{\mathrm{mg}}$ is the 


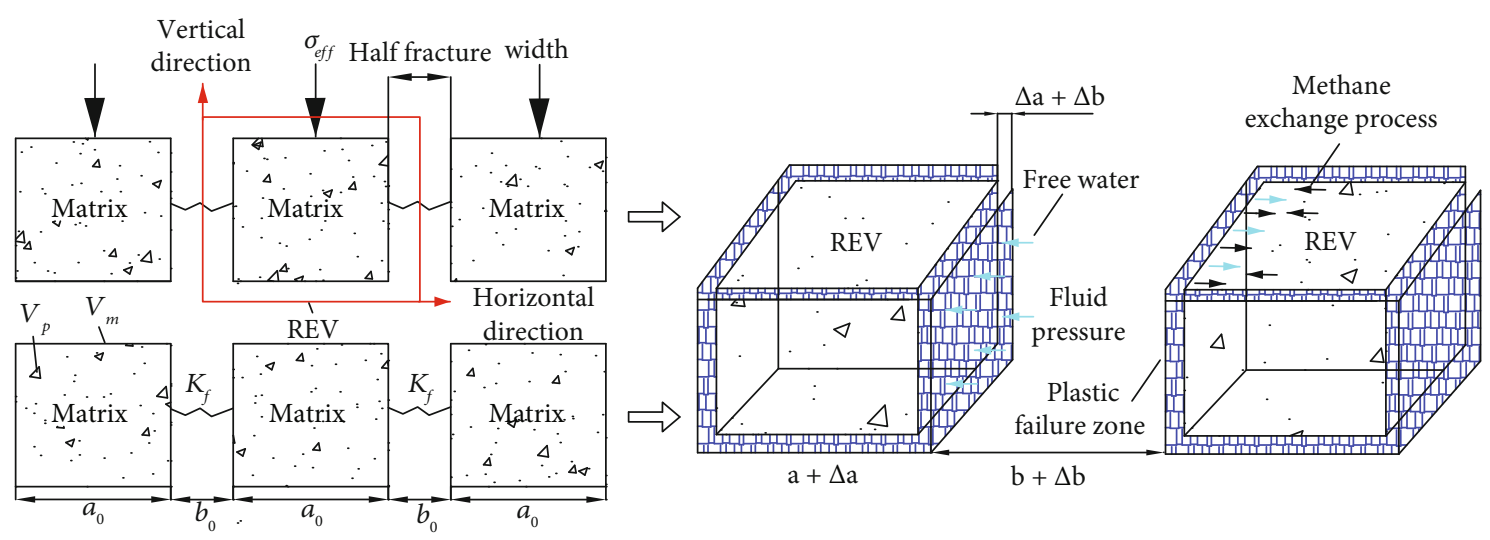

FIgURE 4: Sketch of a coal matrix with a REV.

gas pressure in the matrix. $\phi_{m}$ and $\phi_{f}$ are the porosity in the matrix and fracture, respectively. $\rho_{\mathrm{fw}}$ is the free water density. $S_{\mathrm{fg}}$ and $S_{\mathrm{fw}}$ are the saturation of gas and water in the fracture.

When free water is injected into the coal seam, convection and diffusion are the main modes of fluid flow. The fluid pressure in every point of the coal seam changes with time. Therefore, the mass balance equations of gas and water can be obtained [19].

$$
\begin{gathered}
\frac{\partial M_{\mathrm{mg}}}{\partial t}-\nabla\left(v_{\mathrm{mg}} \cdot \rho_{\mathrm{mg}}\right)-\nabla\left(D_{\mathrm{mg}} \cdot \nabla M_{\mathrm{mg}}\right)=0, \\
\frac{\partial M_{\mathrm{fg}}}{\partial t}-\nabla\left(v_{\mathrm{fg}} \cdot \rho_{\mathrm{fg}}\right)-\nabla\left(D_{\mathrm{fg}} \cdot \nabla M_{\mathrm{fg}}\right)=0, \\
\frac{\partial M_{\mathrm{fw}}}{\partial t}-\nabla\left(v_{\mathrm{fw}} \cdot \rho_{\mathrm{fw}}-g \Delta H\right)=0,
\end{gathered}
$$

where $M$ is the fluid mass. $v$ is the fluid seepage velocity, and $D$ is the diffusion coefficient of gas.

In the fluid mass balance equations (Equations (6)-(8)), the free water and gas seepage velocity are affected by the relative permeabilities $k_{\mathrm{rw}}$ and $k_{\mathrm{rg}}$, the fracture permeability $k_{f}$, and fluid pressures $P_{\mathrm{fw}}$ and $P_{\mathrm{fg}}$. Hence, the seepage velocity of gas and water in the fracture can be defined as follows:

$$
\begin{gathered}
v_{\mathrm{fw}}=-\left(\frac{k_{f} k_{\mathrm{rw}}}{u_{w}}\right) \nabla P_{\mathrm{fw}}, \\
v_{\mathrm{fg}}=-\left(\frac{k_{f} k_{\mathrm{rg}}}{u_{g}}\right) \nabla P_{\mathrm{fg}}, \\
v_{\mathrm{mg}}=-\left(\frac{k_{m}}{u_{g}}\right) \nabla P_{\mathrm{mg}},
\end{gathered}
$$

where $u_{w}$ and $u_{g}$ are the viscosities of gas and water, respectively.

Based on this assumption, free water is considered an incompressible fluid, while the gas density changes with time. According to the ideal gas law, the gas density can be defined as follows:

$$
\rho_{\mathrm{fg}}=\frac{M_{\mathrm{g}} P_{\mathrm{fg}}}{R T} .
$$

Here, $M_{g}$ is the molecular mass of the gas. $R$ is the universal gas constant, and $T$ is the absolute gas temperature. Substituting Equations (9)-(12) into Equations (6)-(8), the governing equations for gas and water flow in a dual-porosity medium are obtained as follows:

$$
\begin{gathered}
{\left[\phi_{m}+\rho_{c} p_{\mathrm{ga}} \frac{V_{L} P_{L}}{\left(P_{\mathrm{mg}}+P_{L}\right)^{2}} e^{(-\lambda \theta)}\right] \frac{\partial P_{\mathrm{mg}}}{\partial t}+P_{\mathrm{mg}} \frac{\partial \phi_{m}}{\partial t}} \\
=\nabla\left(P_{\mathrm{mg}} \frac{k_{m}}{u_{g}} \nabla P_{\mathrm{mg}}\right)+\nabla\left(D_{\mathrm{mg}} \phi_{m} \nabla M_{\mathrm{mg}}\right)-\omega\left(P_{\mathrm{mg}}-P_{\mathrm{fg}}\right), \\
\phi_{f} S_{\mathrm{fg}} \frac{\partial P_{\mathrm{fg}}}{\partial t}+P_{\mathrm{fg}} S_{\mathrm{fg}} \frac{\partial \phi_{f}}{\partial t}+\phi_{f} P_{\mathrm{fg}} \frac{\partial S_{\mathrm{fg}}}{\partial t}=\nabla\left(P_{\mathrm{fg}} \frac{k_{f} k_{\mathrm{rg}}}{u_{g}} \nabla P_{\mathrm{fg}}\right) \\
+\nabla\left(D_{\mathrm{fg}} \cdot \nabla M_{\mathrm{fg}}\right)+\omega\left(P_{\mathrm{mg}}-P_{\mathrm{fg}}\right), \\
\phi_{f} S_{\mathrm{fw}} \rho_{\mathrm{fw}}+S_{\mathrm{fw}} \rho_{\mathrm{fw}} \frac{\partial \phi_{f}}{\partial t}+\phi_{f} \rho_{\mathrm{fw}} \frac{\partial S_{\mathrm{fw}}}{\partial t} \\
-\nabla\left(P_{\mathrm{fw}} \frac{k_{f} k_{\mathrm{rw}}}{u} \nabla P_{\mathrm{fw}}-g \Delta H\right)=0
\end{gathered}
$$

where $a_{0}$ is the initial fracture aperture, $g$ is the gravity, and $\omega$ is the transfer coefficient between the matrix and fracture, which can be defined as follows [20]:

$$
\omega=8\left(1+\frac{2}{a_{0}^{2}}\right) \frac{k_{m}}{\mu} .
$$

3.3. Dynamic Porosity and Permeability Models. The porosity and permeability of the fracture are controlled primarily by the aperture of the fractures. To analyze the 
change in fracture aperture, we consider a representative elemental volume (REV) from the dual-porosity model as an example. As shown in Figure 4, the matrix block fills the center of the repeating REV with a half fracture surrounding the matrix block on all sides. The deformation of REV includes the deformation of horizontal and vertical fractures and the deformation of the matrix block.

Based on our previous work [21], the dynamic porosity and permeability models for the coal matrix can be defined as follows:

$$
\begin{gathered}
\frac{\phi_{m}}{\phi_{m 0}}=1-\frac{N \alpha}{\phi_{m 0} K}\left[\frac{\varepsilon_{L} P_{L}\left(P_{\mathrm{mg}}-P_{\mathrm{mg} 0}\right)}{\left(P_{\mathrm{mg}}+P_{L}\right)\left(P_{\mathrm{mg} 0}+P_{L}\right)} e^{(-\lambda \theta)}-\varepsilon_{v}\right], \\
\frac{k_{m}}{k_{m 0}}=\left(\frac{\phi_{m}}{\phi_{m 0}}\right)^{3}=\left[1-\frac{N \alpha}{\phi_{m 0} K}\left[\frac{\varepsilon_{L} P_{L}\left(P_{\mathrm{mg}}-P_{\mathrm{mg} 0}\right)}{\left(P_{\mathrm{mg}}+P_{L}\right)\left(P_{\mathrm{mg} 0}+P_{L}\right)} e^{(-\lambda \theta)}-\varepsilon_{v}\right]\right]^{3},
\end{gathered}
$$

where $N=\left(\left(b_{0} / a_{0} K_{f}\right)+(1 / K)\right)^{-1}$.

The dynamic porosity and permeability models for coal fracture can be defined as follows:

$$
\begin{gathered}
\frac{\phi_{f}}{\phi_{f 0}}=1-B\left(\frac{\varepsilon_{L} P_{L}\left(P_{\mathrm{mg}}-P_{\mathrm{mg} 0}\right)}{\left(P_{\mathrm{mg}}+P_{L}\right)\left(P_{\mathrm{mg} 0}+P_{L}\right)} e^{(-\lambda \theta)}-\varepsilon_{v}\right), \\
\frac{k_{f}}{k_{f 0}}=\left(\frac{\phi_{f}}{\phi_{f 0}}\right)^{3}=\left[1-B\left(\frac{\varepsilon_{L} P_{L}\left(P_{\mathrm{mg}}-P_{\mathrm{mg} 0}\right)}{\left(P_{\mathrm{mg}}+P_{L}\right)\left(P_{\mathrm{mg} 0}+P_{L}\right)} e^{(-\lambda \theta)}-\varepsilon_{v}\right)\right]^{3},
\end{gathered}
$$

where $B=3 K /\left(K \phi_{f 0}+3 K_{f}\right)$.

3.4. Auxiliary Equations for Two-Phase Flow. In this paper, the van Genuchten model [22] is taken to analyze the component change in two-phase flow. Before water is injected into the coal seam, the fractures are full of free gas, and the gas saturation is 1 . With increasing water injection time, the saturation of free water increases gradually from 0 to $S_{\mathrm{fw}}$. The change equation for saturation of all component fluids in the fracture can be defined as follows:

$$
S_{\mathrm{fg}}+S_{\mathrm{fw}}=1,
$$

where $S_{\mathrm{fg}}$ and $S_{\mathrm{fw}}$ are the saturation of gas and water, respectively. The transport rates of water and gas in the fracture are not the same due to the different pressures and viscosities. Thus, the capillary pressure between water and gas should be taken into account. The capillary pressure can be defined as follows:

$$
P_{c}=P_{\mathrm{fg}}-P_{\mathrm{fw}} .
$$

The water content in fracture $C_{\mathrm{fw}}$ and the concentration of gas $C_{\mathrm{fg}}$ can be written as a function of saturation and capillary pressure.

$$
\begin{aligned}
& C_{\mathrm{fw}}=\phi_{f} \frac{\partial S_{\mathrm{fw}}}{\partial P_{c}}, \\
& C_{\mathrm{fg}}=\phi_{f} \frac{\partial\left(1-S_{\mathrm{fw}}\right)}{\partial P_{c}}=-C_{\mathrm{fw}} .
\end{aligned}
$$

Based on the van Genuchten model, the water saturation $S_{\mathrm{fw}}$, water content $C_{\mathrm{fw}}$, and relative permeability $k_{\mathrm{rw}}$ can be defined as follows:

$$
\begin{aligned}
S_{\mathrm{fw}} & = \begin{cases}\frac{1}{\left[1+\left|\gamma H_{c}\right|^{n}\right]^{m}}, & H_{c}>0, \\
1, & H_{c} \leq 0,\end{cases} \\
C_{\mathrm{fw}} & = \begin{cases}\frac{\gamma m}{1-m}\left(\phi_{f}\right) S_{\mathrm{fw}}^{1 / m}\left(1-S_{\mathrm{fw}}^{1 / m}\right)^{m}, & H_{c}>0, \\
0, & H_{c} \leq 0,\end{cases} \\
k_{\mathrm{rw}} & = \begin{cases}S_{\mathrm{fw}}^{L}\left[1-\left(1-S_{\mathrm{fw}}^{1 / m}\right)^{m}\right]^{2}, & H_{c}>0, \\
1, & H_{c} \leq 0,\end{cases} \\
k_{\mathrm{rg}} & =\left(1-S_{\mathrm{fw}}\right)^{L}\left[1-\left(1-S_{\mathrm{fw}}^{1 / m}\right)^{m}\right]^{2},
\end{aligned}
$$

where $\gamma, n, m$, and $L$ are the characteristic parameters of the coal seam. $H_{c}$ is the water head, $H_{c}=P_{c} / \rho_{w} \times g$.

Substituting Equations (23) and (24) into Equations (14) and (15) yields the governing equations of flows for gas and water in a fracture.

$$
\begin{gathered}
\phi_{f} S_{\mathrm{fg}} \frac{\partial P_{\mathrm{fg}}}{\partial t}+P_{\mathrm{fg}} S_{\mathrm{fg}} \frac{\partial \phi_{f}}{\partial t}-P_{\mathrm{fg}} C_{\mathrm{fw}} \frac{\partial P_{c}}{\partial t}=\nabla\left(P_{\mathrm{fg}} \frac{k_{f} k_{\mathrm{rg}}}{u_{g}} \nabla P_{\mathrm{fg}}\right) \\
+\nabla\left(D_{\mathrm{fg}} \cdot \nabla M_{\mathrm{fg}}\right)+\omega\left(P_{\mathrm{mg}}-P_{\mathrm{fg}}\right) \\
\phi_{f} S_{\mathrm{fw}} \rho_{\mathrm{fw}}+S_{\mathrm{fw}} \rho_{\mathrm{fw}} \frac{\partial \phi_{f}}{\partial t}+\rho_{\mathrm{fw}} C_{\mathrm{fw}} \frac{\partial P_{c}}{\partial t} \\
-\nabla\left(P_{\mathrm{fw}} \frac{k_{f} k_{\mathrm{rw}}}{u} \nabla P_{\mathrm{fw}}-g \Delta H\right)=0
\end{gathered}
$$

3.5. Cross Coupling. For convenience, the governing equation for coal deformation is rewritten as follows:

$$
\begin{aligned}
G u_{i, k k} & +\frac{G}{1-2 v} u_{k, k i}-\alpha P_{\mathrm{mg}, i}-\beta P_{\mathrm{fg}, i}-\beta P_{\mathrm{fw}, i} \\
& -K \frac{P_{L} \varepsilon_{L} P_{\mathrm{mg}, i}}{\left(P_{\mathrm{mg}}+P_{L}\right)^{2}} e^{(-\lambda \theta)}+F_{, i}=0 .
\end{aligned}
$$

Substituting the partial derivatives of $\phi_{m}$ and $\phi_{f}$ with respect to time from Equations (17) and (19) and the permeability Equations (18) and (20) into the gas flow 


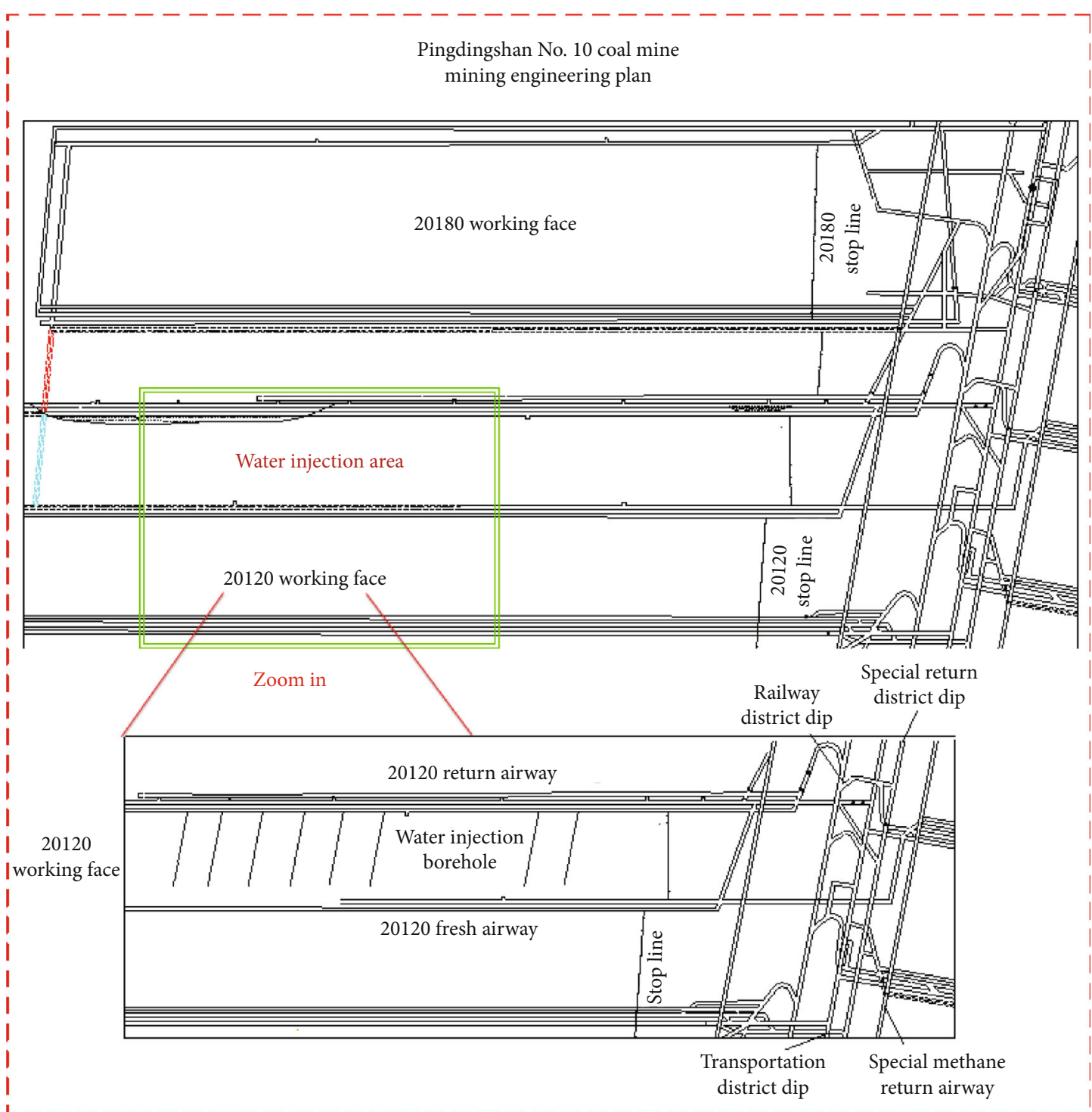

(a)

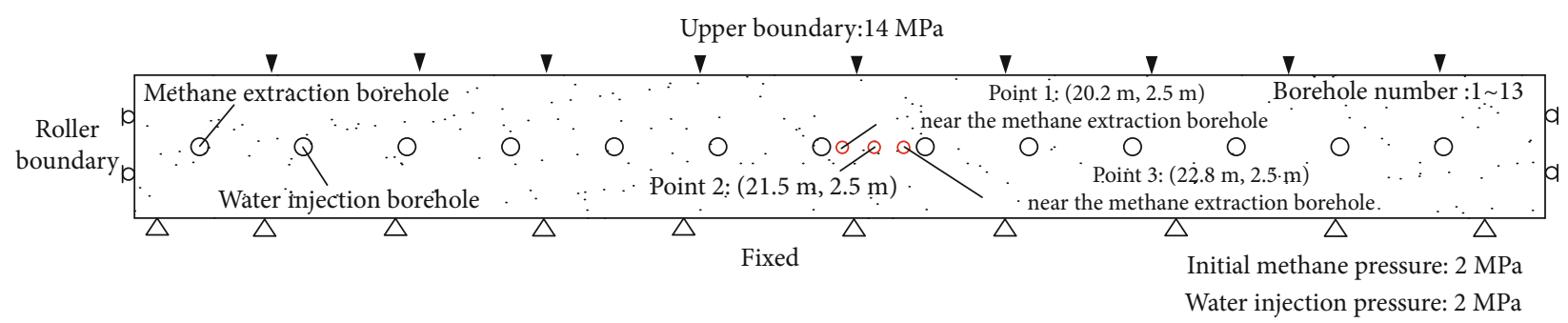

(b)

FIGURE 5: Mining plane graph and simulation model ((a) mining engineering plane; (b) numerical simulation model). 
TABLE 1: Numerical model physical parameters.

\begin{tabular}{|c|c|c|c|}
\hline Parameter & Value & Parameter & Value \\
\hline Coal elastic modulus $E / G P a$ & From Figure 1(a) & Adsorption pressure constant $P_{L} / \mathrm{MPa}$ & 2.07 \\
\hline Compressive strength $\sigma_{c} / \mathrm{MPa}$ & From Figure 2(a) & Adsorption volume constant $V_{L} / \mathrm{m}^{3} / \mathrm{kg}$ & 0.0256 \\
\hline Poisson ratio $v$ & 0.34 & Adsorption pressure strain $\varepsilon_{L}$ & 0.0102 \\
\hline Coal density $\rho_{c} / \mathrm{kg} / \mathrm{m}^{3}$ & 1250 & Initial matrix porosity $\varphi_{m 0}$ & 0.05 \\
\hline Air density $/ \mathrm{kg} / \mathrm{m}^{3}$ & 0.717 & Initial matrix permeability $k_{m 0}$ & $2.8 \cdot 10^{-18}$ \\
\hline Facture stiffness $K_{f} / \mathrm{MPa}$ & 4800 & Methane diffusion rate $D_{\mathrm{n}} / \mathrm{m}^{2}$ & $3.6 \cdot 10^{-12}$ \\
\hline Dynamic viscosity $\mu / \mathrm{Pa} \cdot \mathrm{s}$ & $1.84 \cdot 10^{-5}$ & Initial fracture porosity $\varphi_{f 0}$ & 0.002 \\
\hline Bulk modulus $K / \mathrm{MPa}$ & 5400 & Initial fracture permeability $k_{f 0}$ & $2.08 \cdot 10^{-17}$ \\
\hline Matrix width $a_{0} / \mathrm{m}$ & $5 \cdot 10^{-6}$ & Initial temperature $T / \mathrm{K}$ & 300 \\
\hline Fracture width $b_{0} / \mathrm{m}$ & 0.005 & Water injection pressure $p_{\mathrm{fw}} / \mathrm{MPa}$ & 2 \\
\hline Combined water coefficient $\lambda$ & 14.4 & Initial pore water content $\theta / \%$ & 0.02 \\
\hline Water density $\rho_{w} / \mathrm{kg} / \mathrm{m}^{3}$ & 1000 & Water dynamic viscosity $\mu_{w} / \mathrm{Pa} \cdot \mathrm{s}$ & $1 \cdot 10^{-3}$ \\
\hline Initial gas saturation $S_{\mathrm{fg}}$ & 1 & Initial water saturation $S_{\mathrm{fw}}$ & 0 \\
\hline VG model $\gamma$ & 1.89 & VG model $m$ & 0.54 \\
\hline VG model $n$ & 2.81 & VG model $L$ & 0.5 \\
\hline
\end{tabular}

TABLE 2: Numerical model boundary conditions.

\begin{tabular}{lccc}
\hline Coal seam deformation & Value & Fluid migration & Value \\
\hline Upper boundary/MPa & 14 & Methane extraction pressure/kPa & 20 \\
Lower boundary & Fixed & Water injection pressure/MPa & 2 \\
Left boundary & & Initial water pressure/MPa & 0 \\
Right boundary & Roller support & Initial methane pressure/MPa & 2 \\
Borehole boundary & Free & Water injection time/day & 21 \\
Initial displacement & 0 & & \\
\hline
\end{tabular}

Equations (13), (26), and (27) yields the final fluid flow equations.

$$
\begin{gathered}
{\left[\phi_{m}+\frac{\rho_{c} p_{g a} P_{L} V_{L}}{\left(P_{\mathrm{mg}}+P_{L}\right)^{2}} e^{(-\lambda \theta)}-\frac{\alpha}{K}\left(\frac{1}{K}+\frac{b_{0}}{a_{0} K_{f}}\right)^{-1} \frac{P_{L} \varepsilon_{L} P_{\mathrm{mg}}}{\left(P_{\mathrm{mg}}+P_{L}\right)^{2}} e^{(-\lambda \theta)}\right]} \\
\cdot \frac{\partial P_{\mathrm{mg}}}{\partial t}=\nabla\left(P_{\mathrm{mg}} \frac{k_{m}}{u_{g}} \nabla P_{\mathrm{mg}}\right)+\nabla\left(D_{\mathrm{mg}} \cdot \nabla M_{\mathrm{mg}}\right) \\
+8\left(1+\frac{2}{a_{0}^{2}}\right) \frac{k_{m}}{u_{g}}\left(P_{\mathrm{fg}}-P_{\mathrm{mg}}\right)-\frac{\alpha}{K}\left(\frac{1}{K}+\frac{b_{0}}{a_{0} K_{f}}\right)^{-1} P_{\mathrm{mg}} \frac{\partial \varepsilon_{v}}{\partial t} \\
\phi_{f} S_{\mathrm{fg}} \frac{\partial P_{\mathrm{fg}}}{\partial t}+P_{\mathrm{fg}} S_{\mathrm{fg}} B \frac{\partial \varepsilon_{v}}{\partial t}-P_{\mathrm{fg}} S_{\mathrm{fg}} B \frac{\varepsilon_{L} P_{L} P_{\mathrm{mg}}}{\left(P_{\mathrm{mg}}+P_{L}\right)^{2}} e^{(-\lambda \theta)} \\
\quad-C_{\mathrm{fw}} P_{\mathrm{fg}} \frac{\partial P_{c}}{\partial t}=\nabla\left(P_{\mathrm{fg}} \frac{k_{f} k_{\mathrm{rg}}}{u_{\mathrm{g}}} \nabla P_{\mathrm{fg}}\right)+\nabla\left(D_{\mathrm{fg}} \cdot \nabla M_{\mathrm{fg}}\right) \\
\quad-8\left(1+\frac{2}{a_{0}^{2}}\right) \frac{k_{m}}{u_{g}}\left(P_{\mathrm{fg}}-P_{\mathrm{mg}}\right),
\end{gathered}
$$

$$
\begin{gathered}
\phi_{f} S_{\mathrm{fw}} \rho_{\mathrm{fw}}+\rho_{\mathrm{fw}} S_{\mathrm{fw}} B \frac{\partial \varepsilon_{v}}{\partial t}-\rho_{\mathrm{fw}} S_{\mathrm{fw}} B \frac{P_{L} \varepsilon_{L} P_{\mathrm{mg}}}{\left(P_{\mathrm{mg}}+P_{L}\right)^{2}} e^{(-\lambda \theta)} \\
+C_{\mathrm{fw}} \rho_{\mathrm{fw}} \frac{\partial P_{c}}{\partial t}=\nabla\left(p_{\mathrm{fw}} \frac{k_{f} k_{\mathrm{rw}}}{u_{w}} \nabla p_{\mathrm{fw}}-g \Delta H\right)
\end{gathered}
$$

Equation (29) is the governing equation of gas flow in the coal matrix. In this equation, the first term in the brackets on the left-hand side is the volume of gas released (or sequestered) from the free-phase gas, the second term is the volume of gas released (or sequestered) from the adsorbed-phase gas, and the third term is the volume of gas released (or sequestered) due to coal matrix shrinking or swelling. On the right-hand side, the second term is a coupled term with the pressure associated with the gas flow in the fracture, and the third term is the volume of gas released due to the bulk deformation of the coal. Equation (30) is the governing equation of gas flow in coal fracture. On the left-hand side, the first term is the pressure variation of the gas in the fracture, the second term is the volume of gas released due to the bulk deformation, and the third term is the volume of gas due to coal matrix shrinking. On the right-hand side, the second term is a coupled term related to the pressure associated with 


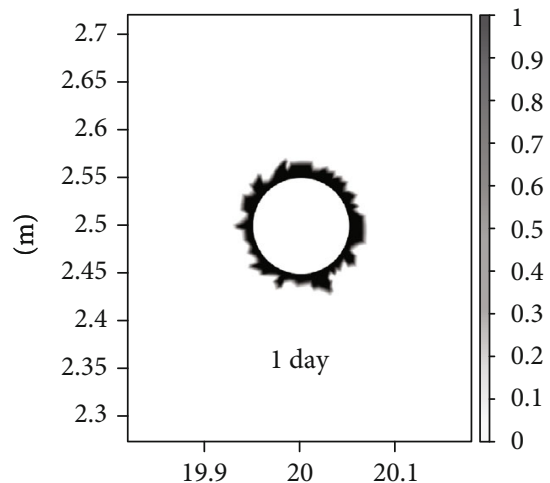

(m)

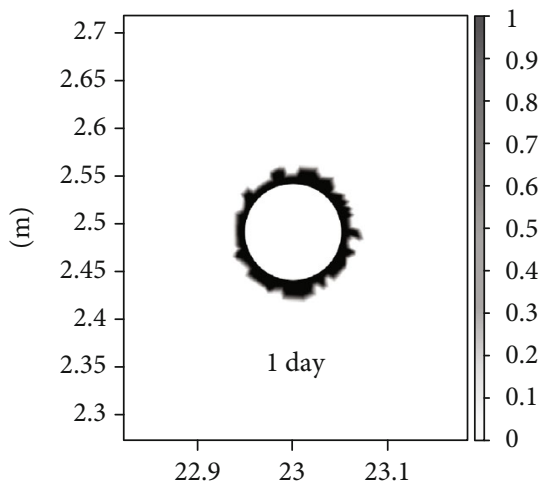

(m)

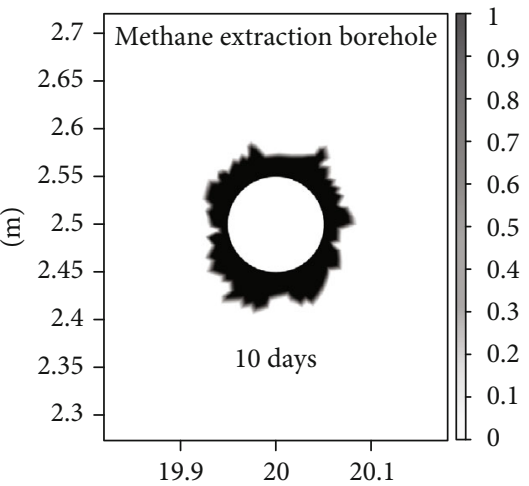

$(\mathrm{m})$

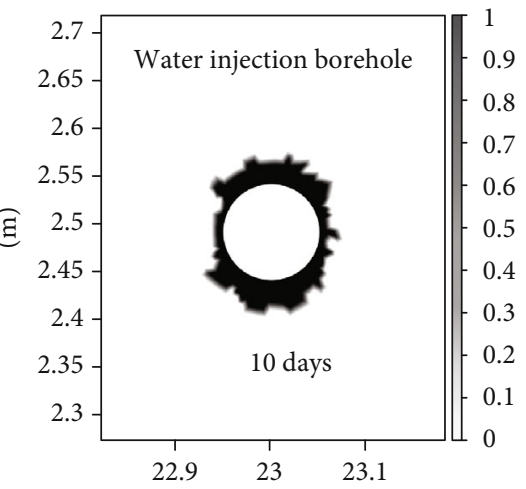

(m)

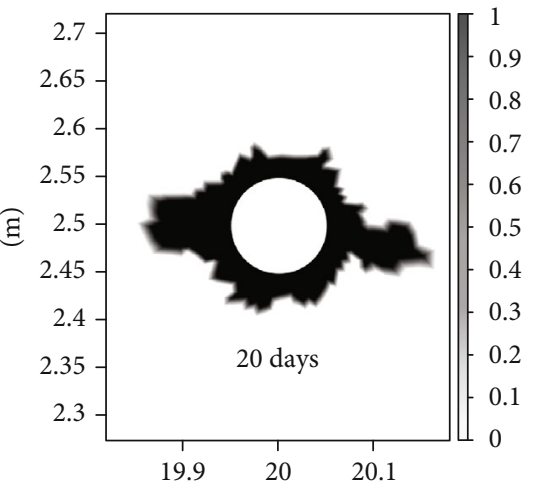

(m)

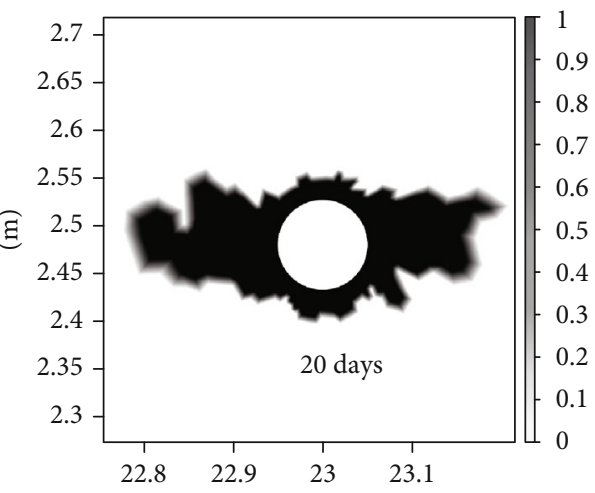

$(\mathrm{m})$

FIGURE 6: Damage zone near the boreholes.

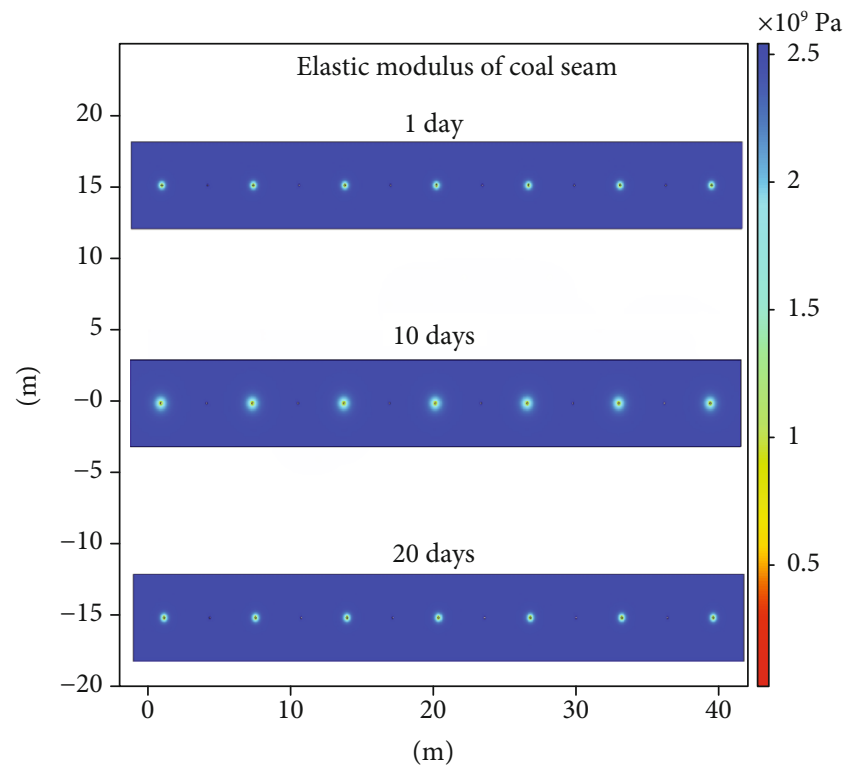

$(\mathrm{m})$

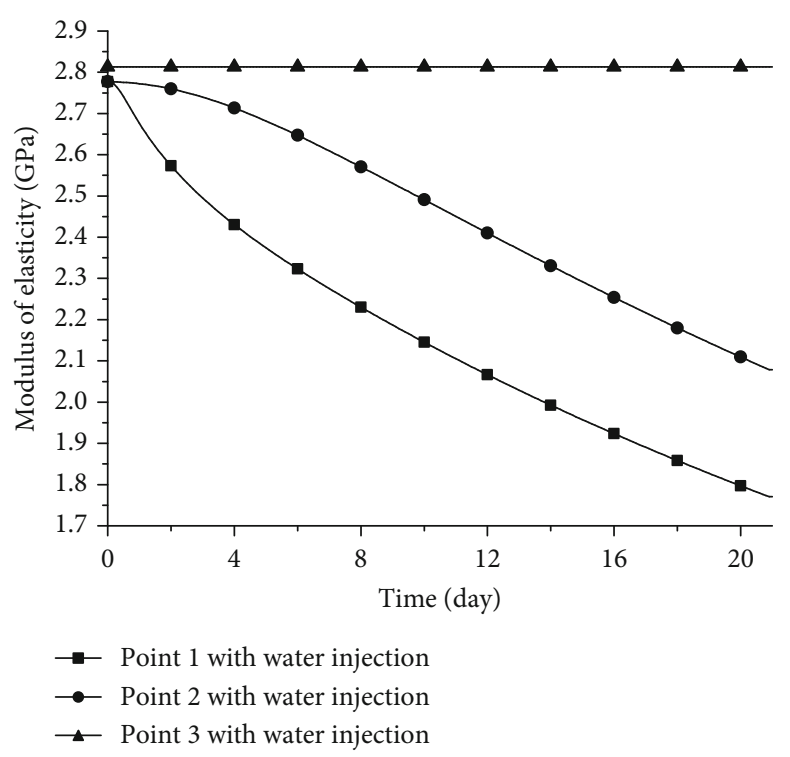

(b)

Figure 7: Elastic modulus changes ((a) contour map; (b) elastic modulus changes). 


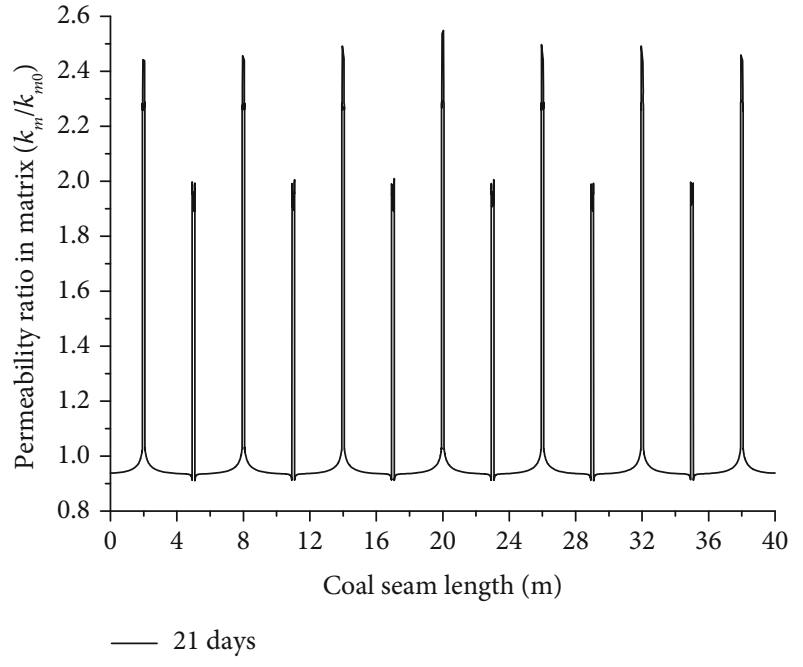

FIGURE 8: The permeability in the coal matrix.

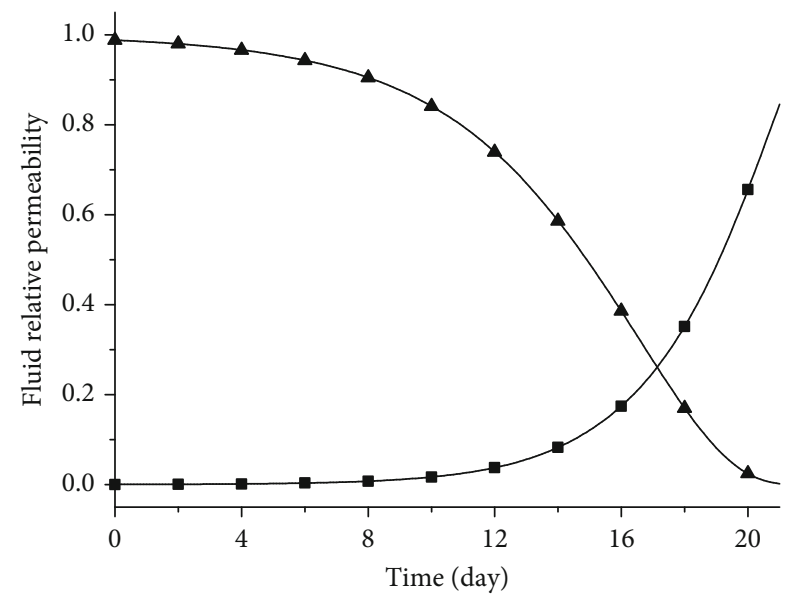

$\rightarrow \quad$ Point 2 water relative permeability

$\leftarrow \quad$ Point 2 methane relative permeability

FIGURE 9: The relative permeability in a coal fracture.

the gas flow in the matrix. Equation (31) is the governing equation of water flow in a coal fracture, and the meanings of each term are the same as in Equation (30).

\section{Simulation of Field Gas Extraction under Water Injection}

4.1. Engineering Background and Simulation Model. The Pingdingshan No. 10 coal mine is an old coal mine with a long mining history in Henan Province, China. The No. 20180 working face is the current mining area, and the No. 20120 working face is the preparing working face next to it. As a high-gas mining face, methane needs to be extracted in advance. However, the low permeability of the coal hinders gas extraction via boreholes. It would take a much longer time to let the gas pressure drop to a safe level if there is no other treatment, which would delay coal production. The

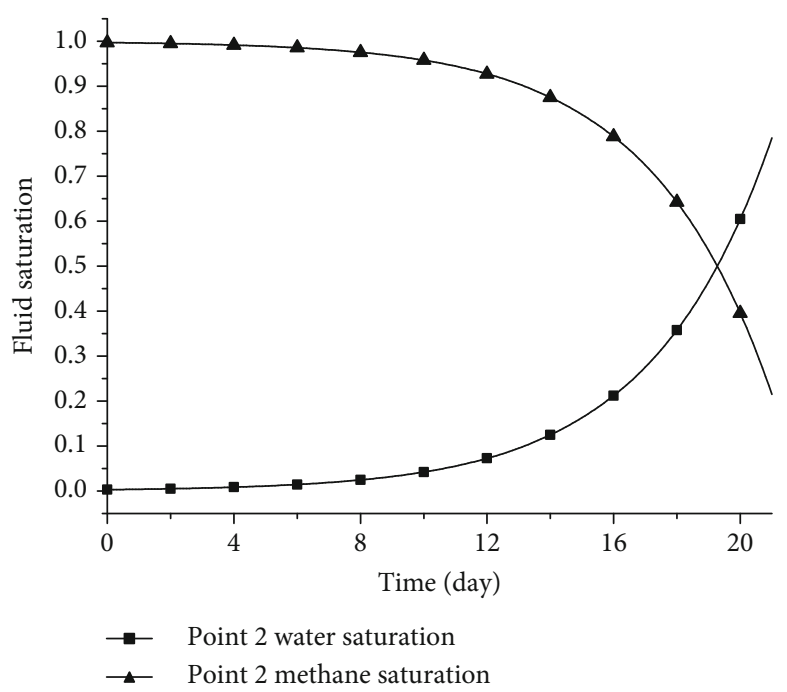

FIgURE 10: Fluid saturation in coal fracture.

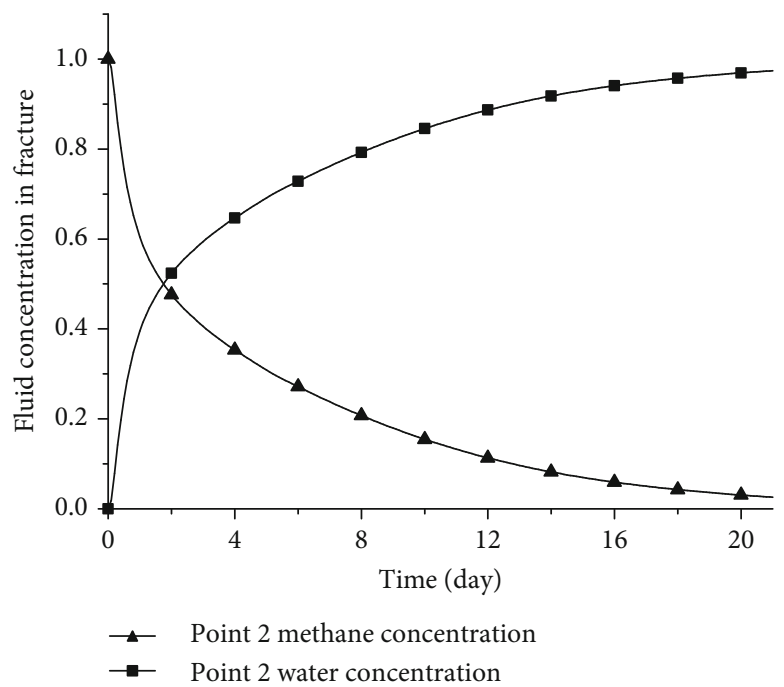

FIgURE 11: Fluid concentration in coal fracture.

engineers want to inject water into the coal seam to speed up the gas drainage, but they are unsure of the results. Thus, we use the model established above to simulate the gas drainage efficiency under water injection.

The mining plane graph of the No. 20120 working face and the numerical model are shown in Figure 5. In Figure 5(b), the length and height of the numerical model are $40 \mathrm{~m}$ and $5 \mathrm{~m}$, respectively, which are used to simulate the geological occurrence of coal seams. There are 13 boreholes in the model with a diameter of $10 \mathrm{~cm}$ and a distance of $3 \mathrm{~m}$. As shown in the numerical model, odd-numbered boreholes are gas extraction boreholes, and even-numbered boreholes are water injection boreholes. The simulation parameters are listed in Table 1, and the boundary conditions are listed in Table 2. Three points in the model $(20.2 \mathrm{~m}$, $2.5 \mathrm{~m}),(21.5 \mathrm{~m}, 2.5 \mathrm{~m})$, and $(22.8 \mathrm{~m}, 2.5 \mathrm{~m})$ were selected and recorded as points 1,2 , and 3 , respectively. These three 


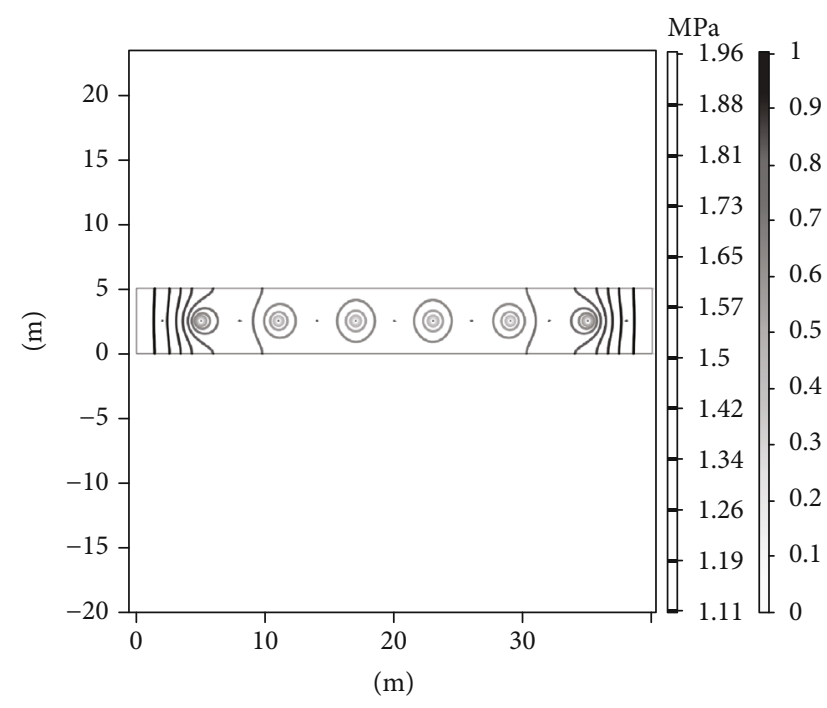

(a)
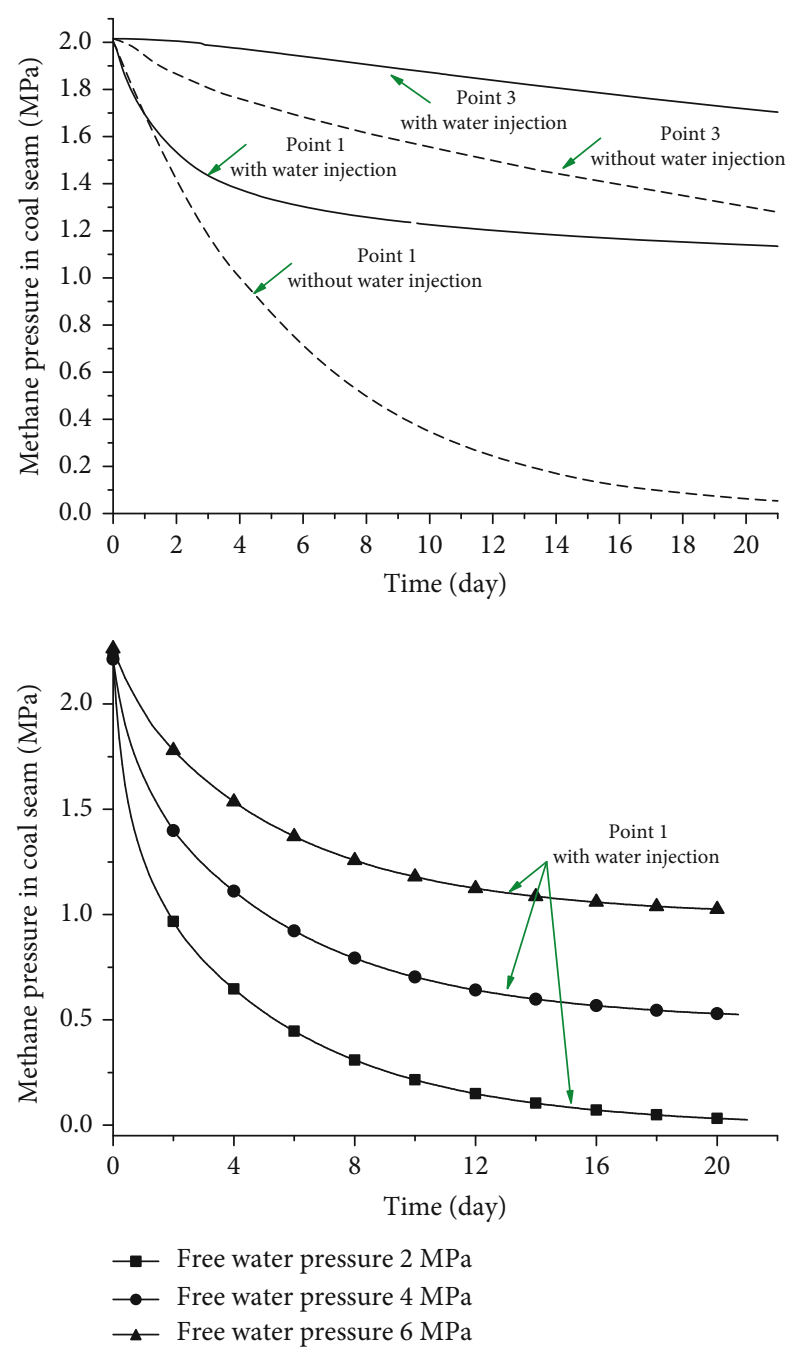

(b)

FiguRE 12: Fluid pressure change with time ((a) free water pressure and plastic failure zone distribution; (b) the influence of free water on methane pressure).

points are used to analyze the changes in fluid parameters during coal seam water injection.

\subsection{Simulation Results and Discussion}

4.2.1. Coal Deformation and Failure. Figure 6 shows the plastic failure zone evolution of boreholes with and without water injection. Excavation of a borehole results in a significant plastic failure zone near the wall of the borehole. When it reaches the end of the water injection time (20th day), the plastic failure range of the gas extraction borehole is approximately 1 times the drilling radius, while the plastic failure range of the water injection borehole is approximately 2 times the borehole radius. It can be seen that the plastic failure zone is much larger with water injection. As discussed in Section 2, the water weakens the mechanical properties of the coal.

Figure 7 shows the drop in the elastic modulus at different locations. Obviously, in this numerical model, the elastic modulus at different boreholes has different trends. Around the water injection borehole, the elastic modulus of the coal seam decreases gradually with time. When the numerical model calculation time reaches the 20th day, the elastic modulus drops to approximately $1.7 \mathrm{GPa}$, while there is no obvious change in the elastic modulus near the gas drainage borehole, and the free water softens the coal seam.

The elastic modulus at point 1 (near the water injection borehole) drops the most, and that at point 3 (near the gas drainage borehole) exhibits almost no change. The results are consistent with Equation (1).

4.2.2. Coal Seam Permeability Change. Figure 8 shows the trend line of permeability in the coal matrix along the model. The permeability ratio of the coal matrix near the water injection borehole increases to approximately 2.5. Near the gas drainage borehole, the value is only 2.0. This illustrates that the plastic failure zone near the water injection borehole is larger and more serious than that near the gas drainage borehole. In addition to the plastic failure zone, the permeability in most areas near the gas drainage borehole is less than 1, 


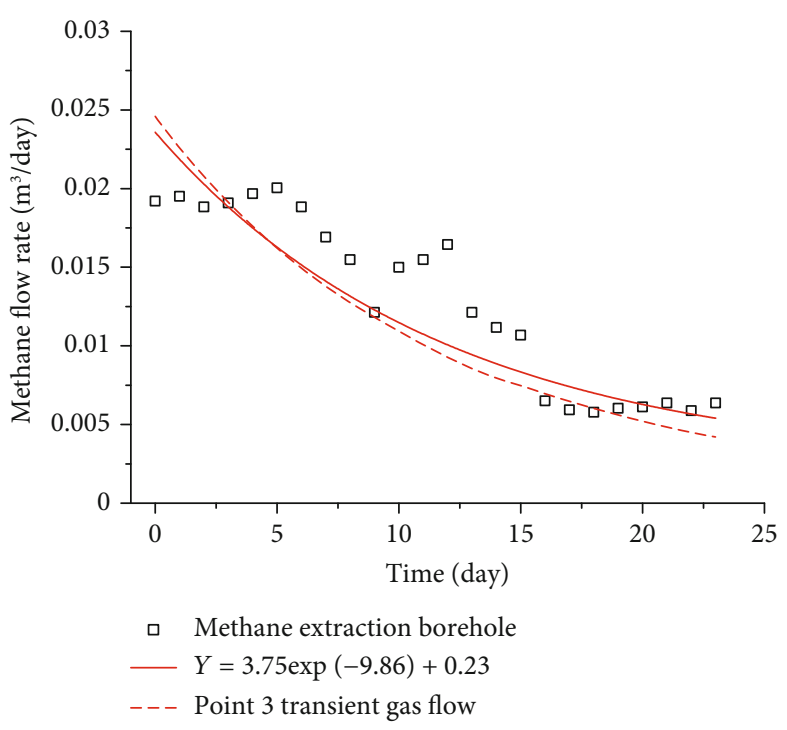

(a)

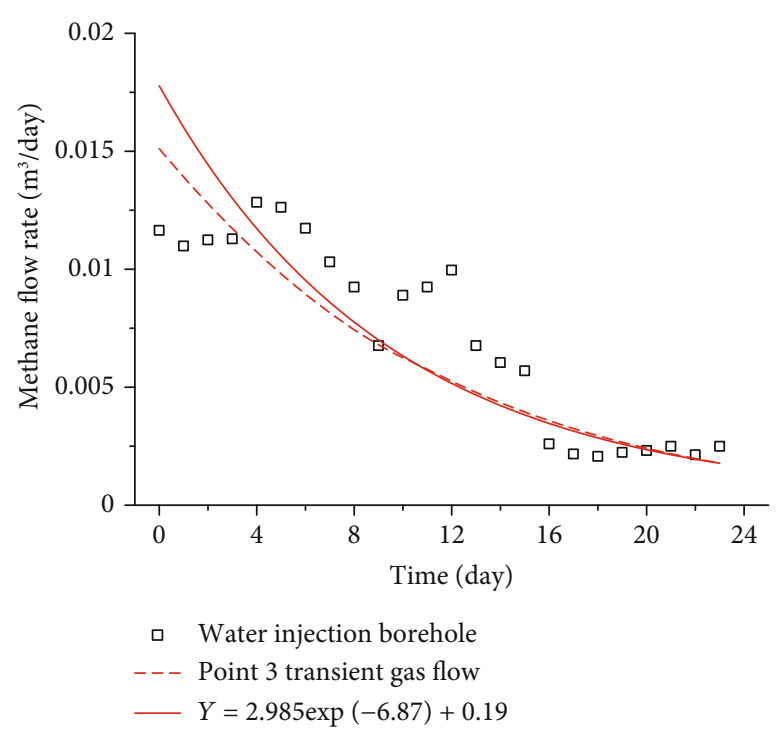

(b)

Figure 13: Gas production rate.

which demonstrates that gas drainage decreases the permeability. In the previous coal seam permeability and solid deformation governing equations (Equations (18), (20), and (28)), the permeability of the coal seam is affected by the coupling effect of plastic failure of the coal seam, gas desorption, and free water flow, which is also the main reason for the different permeability results near water injection boreholes and gas extraction boreholes.

Figure 9 shows the fluid permeability ratios changing in coal fractures. The relative permeability of gas decreases as water is injected, while the relative permeability of water increases. The increase in the relative permeability of free water promotes the flow of the liquid phase in the fracture, which makes it easier for free water to reach saturation quickly. Additionally, the free water relative permeability trend line also demonstrates that the water will block the gas seepage channels.

4.2.3. Changes in Fluid Components in a Fracture. To see how the gas and water contents change, the fluid saturation and concentration in coal fracture at point 2 are plotted in Figures 10 and 11 . Figure 10 shows that as the water injection time increases, the free water saturation in coal fracture increases. With the continuous increase in free water saturation, the gas saturation in the drainage borehole continuously decreases. As the fracture space is gradually filled with free water, the gas migration channel is occupied, which restrains gas movement to the drainage borehole. However, Figure 11 shows that the gas concentration decreases much faster than the drop in gas saturation, which means that before the water occupies the fracture space, the gas has already escaped.

4.2.4. Fluid Pressure and Production. Figure 12 shows the water and gas pressure distribution, shown as the dotted line for point 1 . In the plastic failure zone near the water injection borehole, the softening effect of free water causes the original fracture to be continuously destroyed and expanded, which improves the permeability of the coal seam and promotes the gas pressure drop. When there is no free water injection, it takes 8 days to drop to a safe pressure of less than $0.75 \mathrm{MPa}$. On the other hand, when free water enters the free water wetting zone far from the water injection borehole (point 3), the free water completely occupies the fracture space; on the basis of reducing the gas saturation, it hinders the flow of gas in the fracture and significantly reduces the velocity of the gas pressure drop. At point 1, the coal seam gas pressure drops to only approximately $1.2 \mathrm{MPa}$. During the gas drainage process, there is a significant competition phenomenon related to the gas pressure drop in the coal seam. The change in gas pressure is the result of the interaction of free water and coal seam permeability.

After water injection in working face 20120, we recorded gas concentration data in the \#1 gas drainage borehole and \#2 water injection borehole. As shown in Figure 13, in the water injection borehole, the gas concentration in the extraction pipe rapidly drops from approximately $3.5 \%$ to $1.5 \%$, and the influence of free water on gas flow becomes more prominent. Compared with adjacent drainage boreholes, with the expansion of the wetting radius of free water, the influence of free water on gas is more prominent. After drilling (0-4 days), the expansion of the plastic failure zone in the coal seam prompts the free gas to flow rapidly into the borehole, which makes the gas concentration approximately $3 \%$. However, in regard to the later stage of extraction (8-16 days), under the action of long-term water injection, the free water inhibits the desorption of the adsorbed gas and increases the resistance of the gas flowing in the fracture, forcing the gas concentration in the extraction borehole to decrease to approximately $1 \%$. Compared with the curve of gas concentration in the model, the curve of gas concentration in different boreholes is generally in a downward stage, but the downward trend of the curve is affected by the geological conditions of the coal seam and free water flow. This is the main 
reason for the discreteness between the numerical model results and the collected data.

\section{Discussion}

In this paper, the softening effect of free water on the mechanical strength of coal samples was verified by water injection experiments and uniaxial compression experiments of coal samples. Then, based on the relevant two-phase flow theory, a gas-liquid-solid coupling model for gas drainage under coal seam water injection was established.

In the existing research on coal seam water injection to eliminate gas disasters, according to different research contents, it can be divided into the following two types. The first is to study the influence of water injection on the mechanical strength of coal seam. On this basis, the plastic failure zone change of coal seam under abutment pressure is discussed. In another type of research, it focuses on the effect of free water on gas transport. Therefore, in the existing research, there is currently no mathematical model describing the effects of coal seam water injection on gas drainage that combines these two aspects. As the numerical model results show, the softening and destruction effects of free water on coal seams are distinguished. Based on this, the effect of free water on gas flow is further studied, and it turns out that the existence of free water increases the resistance of gas flow. Of course, it must be pointed out that, in further research, permeability experiments containing extra coal samples need to be conducted.

\section{Conclusion}

In this study, we aimed to better understand the influence of water injection on gas drainage in coal seams. A series of experiments were conducted to study the differences in mechanical property changes under wetting conditions with different coal samples. Based on the experimental results, a gas-liquid-solid coupling model including effective stress change and gas desorption is established. The model is used to simulate the field gas extraction in the 20120 working face in the Pingdingshan No. 10 coal mine, and the results are validated with field data. The main research conclusions are as follows:

(1) Water injection can weaken the mechanical properties of coal. The experimental results show that the elastic modulus and compressive strength decrease as an exponential function with increasing water pressure

(2) Based on the gas-liquid-solid coupling model, the permeability, elastic modulus, and gas pressure in different reaction areas (plastic failure zone and water wetting zone) induced by water injection are analyzed. In the plastic failure zone, the permeability of the coal seam increases, which allows gas to flow into the extraction borehole and eliminates the danger of a gas outburst
(3) There is a significant competition phenomenon for the pressure drop when water is injected into the coal seam. On the one hand, the water pressure will weaken the properties of coal and decrease the effective stress in the coal seam, which will increase permeability and accelerate gas flow. On the other hand, the free water will occupy the fracture space, which blocks the gas migration channel. The overall effect of water injection on gas extraction depends on which impact plays a dominant role

(4) Combined with the gas flow data of boreholes \# 1 and \#2 collected on site, the results of the gas-liquid-solid coupling model matched the field results. Although there is dispersion between the on-site flow data and the coupled model data, the downward trend of the flow trend lines is consistent. The established drainage model better reflects the law of borehole damage and gas drainage under water injection

\section{Data Availability}

The data used to support the findings of this study are available from the corresponding author upon request.

\section{Conflicts of Interest}

The authors declare that they have no conflicts of interest.

\section{Acknowledgments}

This work was supported by the Chinese National Natural Science Foundation (U1803118), the National Natural Science Foundation of China (No. 51974296), and the Central Universities (China University of Mining and Technology) with Grant 2015XKZD06. The sources of this support are gratefully acknowledged.

\section{References}

[1] J. Dong, Y. Cheng, J. Kan et al., "Effects of diffusion and suction negative pressure on coalbed methane extraction and a new measure to increase the methane utilization rate," Fuel, vol. 197, no. Complete, pp. 70-81, 2017.

[2] R. Pan, Y. Cheng, Y. Liang, M. Yu, and J. Dong, "Effect of bedding structural diversity of coal on permeability evolution and gas disasters control with coal mining," Natural Hazards, vol. 73, no. 2, pp. 531-546, 2014.

[3] Y. G. Wang, L. I. Hong-Yan, Q. I. Qing-Xin, Y. W. Peng, L. I. Chun-Rui, and Z. G. Deng, "The evolution of permeability and gas extraction technology in mining coal seam," Journal of China Coal Society, vol. 35, no. 3, pp. 406-410, 2010.

[4] D. M. Zhang, Q. I. Xiao-Han, R. Q. Song, and G. Z. Yin, "Coupling mechanism of rock mass stress and gas flow in coal mining fissures," Journal of China Coal Society, vol. 40, no. 4, pp. 774-780, 2015.

[5] D. G. Fredlund, A. Xing, and S. Huang, "Predicting the permeability function for unsaturated soils using the soilwater characteristic curve," Canadian Geotechnical Journal, vol. 31, no. 4, p. 159A, 1994. 
[6] S. H. Ji, Y. J. Park, and K. K. Lee, "Influence of fracture connectivity and characterization level on the uncertainty of the equivalent permeability in statistically conceptualized fracture networks," Transport in Porous Media, vol. 87, no. 2, pp. 385395, 2011.

[7] K. Kishida, A. Sawada, H. Yasuhara, and T. Hosoda, "Estimation of fracture flow considering the inhomogeneous structure of single rock fractures," Soils and Foundations, vol. 53, no. 1, pp. 105-116, 2013.

[8] H. Deng, L. I. Jianlin, X. Sun, M. Zhu, X. Yuan, and Q. Luo, "Experimental research on fracture mechanical effect of sandstone under water corrosion," Chinese Journal of Rock Mechanics, vol. 31, no. 7, pp. 1342-1348, 2012.

[9] C. Bo, J. Tong, J. Bo, and K. Yin, "How does the water-rock interaction of marly rocks affect its mechanical properties in the Three Gorges reservoir area, China," Environmental Earth Sciences, vol. 72, no. 8, pp. 2797-2810, 2014.

[10] J. Zhang, W. B. Standifird, J. C. Roegiers, and Y. Zhang, "Stress-dependent fluid flow and permeability in fractured media: from lab experiments to engineering applications," Rock Mechanics Rock Engineering, vol. 40, no. 1, pp. 3-21, 2007.

[11] S. J. Peng, J. Xu, H. W. Yang, and D. Liu, "Experimental study on the influence mechanism of gas seepage on coal and gas outburst disaster," Safety Science, vol. 50, no. 4, pp. 816-821, 2012.

[12] E. A. Letham and R. M. Bustin, "Klinkenberg gas slippage measurements as a means for shale pore structure characterization," Geofluids, vol. 16, no. 2, pp. 264-278, 2016.

[13] M. Oostrom and R. J. Lenhard, "Comparison of relative permeability-saturation-pressure parametric models for infiltration and redistribution of a light nonaqueous-phase liquid in sandy porous media," Advances in Water Resources, vol. 21, no. 2, pp. 145-157, 1998.

[14] X. Jun, L. Yunpei, Z. Quanle, L. Lei, and L. Xuelong, “Elimination of coal and gas outburst risk of low-permeability coal seam using high-pressure water jet slotting technology: a case study in Shihuatian Coal Mine in Guizhou Province," China. Energy Science Engineering, vol. 12, 2019.

[15] H. Xie, X. Jing, M. Gao et al., "Theoretical and experimental validation of mining-enhanced permeability for simultaneous exploitation of coal and gas," Environmental Earth Sciences, vol. 73, no. 10, pp. 5951-5962, 2015.

[16] T. Xia, F. Zhou, J. Liu, S. Hu, and Y. Liu, "A fully coupled coal deformation and compositional flow model for the control of the pre-mining coal seam gas extraction," International Journal of Rock Mechanics Mining Sciences, vol. 72, pp. 138148, 2014.

[17] C. Yuanfang, D. Bingxiang, S. Xian, L. Na, and Y. Zheng, "Seepage mechanism of a triple-porosity/dual-permeability model for shale gas reservoirs," Natural Gas Industry, vol. 32, no. 9, pp. 44-47, 2012.

[18] P. Q. Huy, K. Sasaki, Y. Sugai, and S. Ichikawa, "Carbon dioxide gas permeability of coal core samples and estimation of fracture aperture width," International Journal of Coal Geology, vol. 83, no. 1, pp. 1-10, 2010.

[19] A. Gilman and R. Beckie, "Flow of coal-bed methane to a gallery," Transport in Porous Media, vol. 41, no. 1, pp. 1-16, 2000.

[20] M. S. Masoudian, D. W. Airey, and A. El-Zein, "The role of coal seam properties on coupled processes during CO2seques- tration: a parametric study," Greenhouse Gases Science Technology, vol. 6, no. 4, pp. 492-518, 2016.

[21] W. Yu, J. Liu, D. Elsworth, X. Miao, and X. Mao, "Development of anisotropic permeability during coalbed methane production," Journal of Natural Gas Science Engineering, vol. 2, no. 4, pp. 197-210, 2010.

[22] J. Simunek and M. T. V. Genuchten, "Estimating unsaturated soil hydraulic properties from multiple tension disc infiltrometer data," Soil Science, vol. 162, no. 6, pp. 383-398, 1997. 